\title{
Microhabitat, Activity, and Approach Distances of the San Salvador Bark Anole (Anolis distichus ocior)
}

\author{
Dayton L. Antley, Taylor R. Lind, Brendan T. Gabbart, and Tiffany L. Zinn \\ Department of Biology, Avila University, Kansas City, Missouri 64145, USA
}

T he Bark Anole (Anolis distichus) is a polytypic species (17 currently recognized subspecies) with a broad native distribution in the Bahamas and on Hispaniola and introduced populations in southern Florida (Henderson and Powell 2009). Although the species has been the subject of many studies, little is known about the San Salvador Bark Anole $(A$. d. ocior; Figs. $1 \& 8$ ), which is endemic to San Salvador and Rum Cay in the Bahamas.

Bark Anoles generally are mesophilic but can be xerophilic (Schwartz and Henderson 1991). They are trunk ecomorphs that generally perch on tree trunks or analogs like fence posts or telephone poles, where they feed mainly on ants (Rand and Williams 1969; Schoener 1968, 1979; Schoener and Schoener 1980a; Cullen and Powell 1994). They inhabit a variety of habitats, including forest edges, isolated trees, abandoned agricultural areas, and human-modified habitats that include artificial structures (Powell and Henderson 2009 and references therein). These anoles typically are diurnal and more frequently observed in the sun during early mornings, when they also appear to feed more actively (Rand 1962).

Like most anoles, Bark Anoles exhibit male-biased sexual size dimorphism, with males attaining a maximum SVL of $58.4 \mathrm{~mm}$ and females $50.2 \mathrm{~mm}$ on Bimini and Andros Islands (Schoener 1988). Also like most anoles, Bark Anoles are intensely territorial (e.g., Mertens 1939). On Hispaniola, Rand (1962) noted that two individuals typically occupy a small tree, one is a male that is perched lower than the female; larger trees can support more individuals, but males tend to perch lower than females. If several females are present, the smallest perches higher, and juveniles even higher. Sifers et al. (2001), also on Hispaniola, similarly recorded females on higher perches. However, males perched higher than females on Exuma (Lister 1976) and at other sites on Hispaniola (Fitch et al. 1989; Cast et al. 2000). Paterson (1999) noted that perch heights of males and females in Florida did not differ significantly. Only rarely are individuals found on the ground (Schoener 1968; Lister 1976; Moermond 1979).
Oliver (1948) described Bark Anoles on Bimini as alert and active, remaining in position until an intruder is very close, relying on agility to escape. On Hispaniola, Schneider et al. (2000) recorded mean primary and secondary approach distances of $83.5 \pm 14.7 \mathrm{~cm}$ and $56.5 \pm 15.4 \mathrm{~cm}$, respectively, with "squirreling" the most common response in both cases.

On Hispaniola, Johnson et al. (2008) observed 1.21 moves per minute, and J.B. Losos (in Henderson and Powell 2009) recorded $4.0 \%$ time displaying. Like other anoles, territorial and mating displays include head-bobs, push-ups, and dewlap extensions (Losos 2009).

What little we know about Bark Anoles on San Salvador was summarized in anecdotal observations by Hillbrand et al.

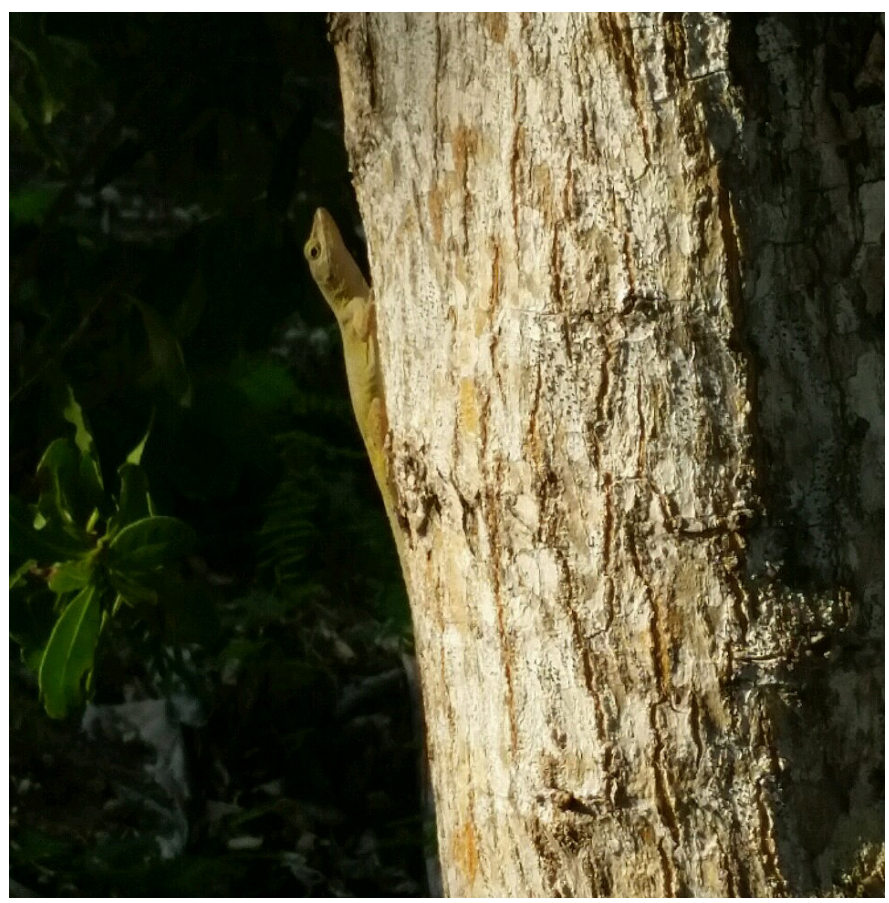

Fig. 1. An adult male Bark Anole (Anolis distichus ocior) basks in the early morning sun at the study site at the Gerace Research Centre on San Salvador Island, The Bahamas. Photograph by Dayton L. Antley. 
(2011), who stated that these anoles are locally abundant, but missing from many areas that lack large trees and deep shade. They often are most active in early morning and late evening, seeking shade during the heat of the day. They frequently "squirrel" to the opposing side of the tree before moving up or down when approached by a potential threat.

From 13-20 May 2015, we conducted surveys and focal animal observations of San Salvador Bark Anoles to test four predictions: (1) Activity will be evident throughout the day but will peak during the morning with a lesser peak during late afternoon; (2) perch heights of adult males will be higher than those of smaller individuals; (3) adult males will tolerate closer approach distances than females and subadult males; and (4) adult males will be more active (move and display at greater frequencies) than smaller individuals.

\section{Methods}

We established a study plot of approximately $15 \times 18 \mathrm{~m}$ on the grounds of the Gerace Research Centre on San Salvador (Figs. 2-3). The plot was a grove comprised of 29 mostly non-native trees (mean dbh $=27.6 \pm 3.4 \mathrm{~cm}, 5-79 \mathrm{~cm}$ ), primarily Tropical Almonds (Terminalia catappa) interspersed with a few Papayas (Carica papaya) and several small Ficus (Ficus sp.). The site was isolated by a road on the west side, a concrete enclosure housing San Salvador Rock Iguanas (Cyclura rileyi rileyi) on the south side, a mowed field on the north side, and short (mostly $<2 \mathrm{~m}$ high) dense scrubby coppice on the east side.

Due to time limitations, we did not attempt to capture and mark individuals. Initial surveys revealed no juveniles and, because subadult males and adult females are difficult to distinguish at a distance, we classified lizards as adult males

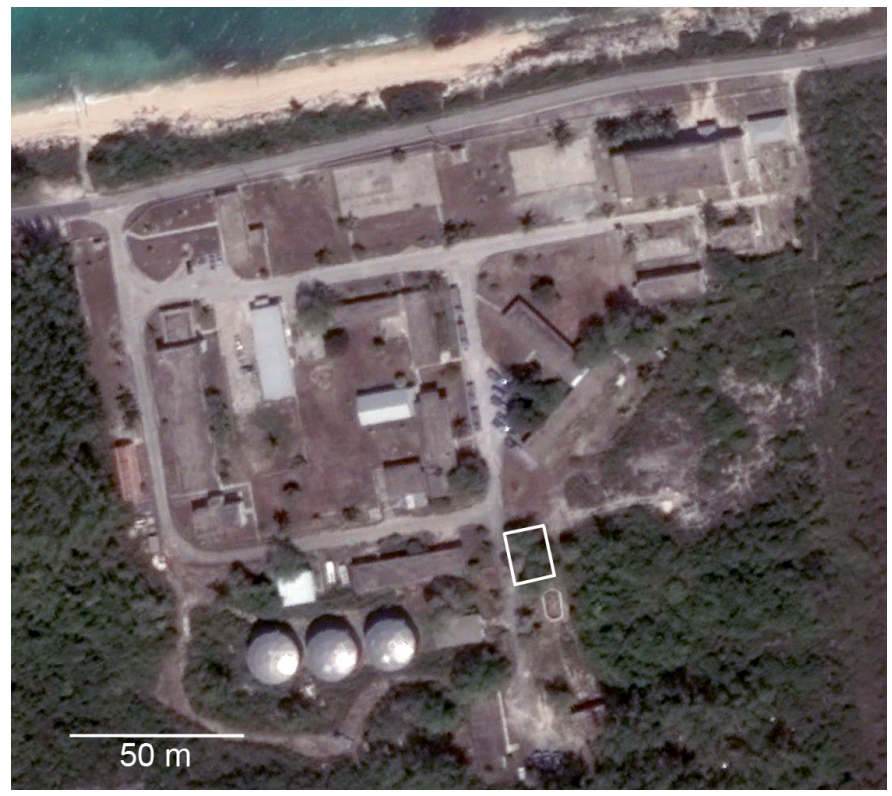

Fig. 2. A Google Map view of the Gerace Research Centre. The study site $\left(24^{\circ} 07^{\prime} 05.2^{\prime \prime} \mathrm{N} 74^{\circ} 27^{\prime} 50.9^{\prime \prime} \mathrm{W}\right)$ is outlined in white.

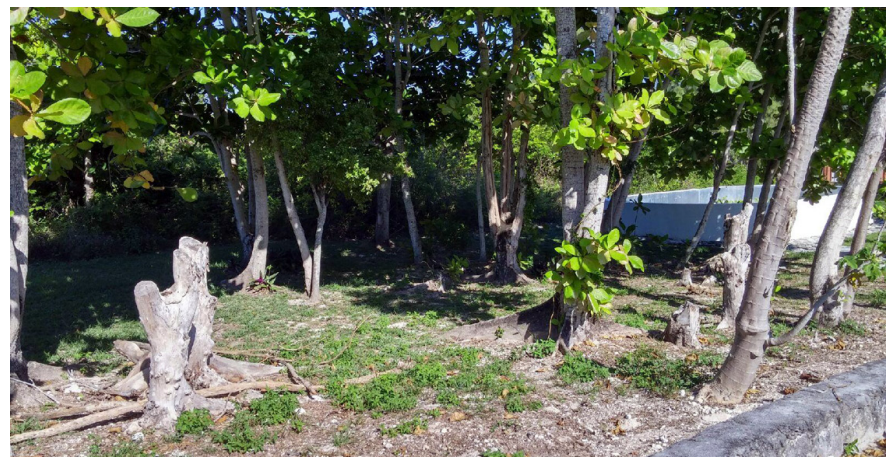

Fig. 3. A view of the study site from the southeast. Note the curb of the road that borders the area on the west and the concrete enclosure housing San Salvador Rock Iguanas (Cyclura rileyi rileyi) to the south. Photograph by Dayton L. Antley.

(Figs. $1 \& 8$ ) or smaller individuals (subadult males and adult and subadult females).

To monitor activity and evaluate microhabitat use throughout the day, we conducted surveys every two hours over a two-day period beginning at $0700 \mathrm{~h}$ (about $40 \mathrm{~min}$ after sunrise) and ending at $1900 \mathrm{~h}$ (about $40 \mathrm{~min}$ before sunset). Before each survey, we recorded ambient temperature one meter above the ground in the shade and sheltered from the wind. During each survey, we counted all lizards seen. To avoid counting the same individual twice during any one survey, we ignored lizards on trees on which we had made previous observations (we observed no lizards moving from one tree to another and, if they did, assumed that they would not have time to do so within that allotted for each survey period). For animals that had not reacted to our presence, we recorded date, time, size class (adult or sub-adult male/ female), tree number, body orientation (facing up or down or perched horizontally), perch height, perch diameter, and insolation (sun/shade/mosaic). Although we undoubtedly recorded data for some of the same individuals at different times or on different days, we contend that these are independent observations as lizards would choose perches based on current conditions.

To determine approach distances, we used the methods of Schneider et al. (2000). On the day following the assessments of microhabitat and activity, the same person wearing neutral colors would approach an undisturbed anole at a steady pace of approximately $0.8-1.0 \mathrm{~m} / \mathrm{sec}$. We recorded the distance at which the animal reacted and noted the initial response ("squirreling," jumping, moving up the tree, or moving down the tree). If the lizard was still visible, we continued the approach to induce a secondary response.

We conducted focal animal observations over two additional days, observing an individual lizard definitively identified as male or female through binoculars for 10 minutes or until it moved out of sight. We maintained a minimal observation distance of $5 \mathrm{~m}$ while recording the number of movements (defined as a change in location or orientation), head 
turns, and head bobs for all lizards, and dewlap displays and pushups for males. To avoid multiple observations of any one lizard, we observed only one lizard per size class per tree.

We used StatView ${ }^{\circledR} 5.0$ (SAS Institute Inc., Cary, North Carolina) for all statistical comparisons, using unpaired t-tests to evaluate perch heights and diameters used by the two different size classes and ambient temperatures at which the two size classes were active, ANOVA to compare perch heights used at different times of day, and, because approach and focal animal data were not normally distributed, nonparametric MannWhitney $U$ tests for comparisons of size classes or sexes. All means are presented \pm one SE. For all tests, $\alpha=0.05$.

\section{Results}

We recorded perch heights and diameters for 130 observations and conducted 37 approaches and 28 focal animal observations. We did not record orientation for all lizards observed. The greatest number of individuals seen during any one survey was 16 . Although a very conservative estimate of the total number of lizards in the plot of $270 \mathrm{~m}^{2}$, this extrapolates to a population density of 593 anoles/ha. Anoles were observed on all but four of the trees in the plot and those on which we saw no lizards were four of the five smallest trees.

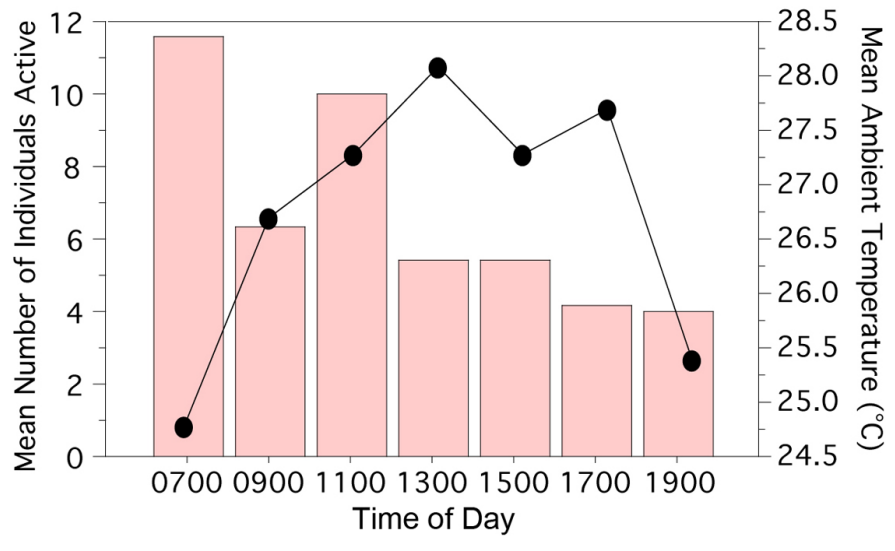

Fig. 4. Mean number of lizards active (bars) and mean ambient temperatures (dots) per time period (see text). Temperature data were collected on two consecutive days.

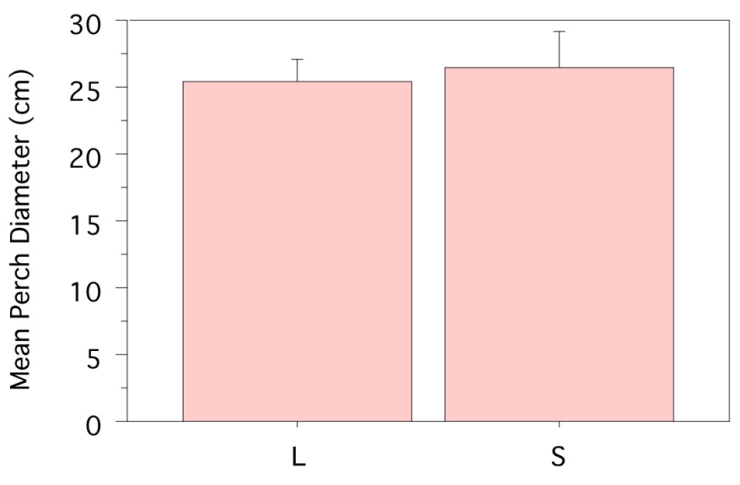

Fig. 6. Mean perch diameters $(\mathrm{cm})$ of adult males $(\mathrm{L})$ and subadult males and females (S).

Lizards were active throughout the day (Fig. 4). The most individuals were active during the morning with numbers decreasing throughout the day and into the evening. The initial decrease corresponded to the warmest time of day.

Mean perch height (Fig. 5) of adult males (117.6 \pm 8.0 $\mathrm{cm}, 0-390 \mathrm{~cm}, \mathrm{n}=88)$ was significantly greater $(\mathrm{df}=128, \mathrm{t}=$ $2.049, \mathrm{P}=0.04)$ than that of smaller individuals $(90.1 \pm 10.0$ $\mathrm{cm}, 0-240 \mathrm{~cm}, \mathrm{n}=42$ ). Only eight individuals (four in each size class) were on the ground; all appeared to be foraging near the base of a tree. We observed no lizards moving across the ground to another tree. Perch heights of adult males were highest at midday but mean heights at different times of day (Fig. 5) did not differ significantly $(\mathrm{df}=6, \mathrm{~F}=0.674, \mathrm{P}=0.67)$. Perch heights of smaller individuals failed to show a similar pattern (Fig. 5) but also did not differ significantly $(\mathrm{df}=6, \mathrm{~F}=0.622, \mathrm{P}$ $=0.71$ ). Mean perch diameters (Fig. 6) for adult males (25.5 \pm $1.5 \mathrm{~cm}, 10-88 \mathrm{~cm}, \mathrm{n}=84)$ and smaller individuals $(26.4 \pm 2.9$ $\mathrm{cm}, 9-88 \mathrm{~cm}, \mathrm{n}=38)$ did not differ significantly $(\mathrm{df}=120, \mathrm{t}=$ $-0.297, \mathrm{P}=0.77$ ), nor did ambient temperatures when lizards in the two size classes (adult males: $26.9 \pm 0.1^{\circ} \mathrm{C}, 23.8-29.4$ ${ }^{\circ} \mathrm{C}, \mathrm{n}=88$; smaller individuals: $26.6 \pm 0.1^{\circ} \mathrm{C}, 23.8-29.4^{\circ} \mathrm{C}, \mathrm{n}$ = 42) were active $(\mathrm{df}=128, \mathrm{t}=0.849, \mathrm{P}=0.40)$.

The vast majority of individuals (102 of 130) observed were in full shade, 18 were in full sun, and only 10 were in a sun-shade mosaic. Most anoles (43 of 79) for which orientation was recorded were facing downward, but many (34) were
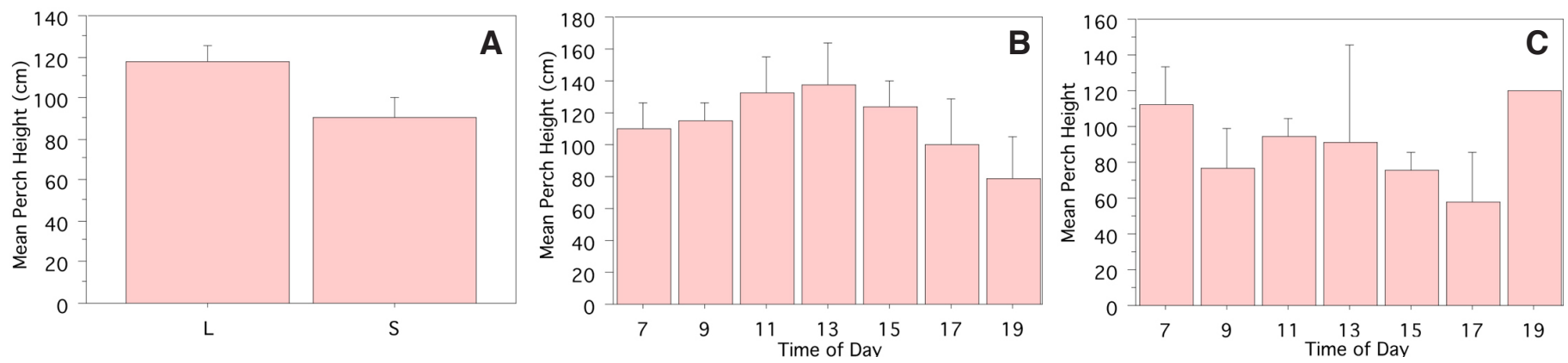

Fig. 5. A: Mean perch heights $(\mathrm{cm})$ of adult males $(\mathrm{L})$ and subadult males and females $(\mathrm{S})$; B: mean perch heights of adult males at different times of day; C: mean perch heights of subadult males and females at different times of day. 

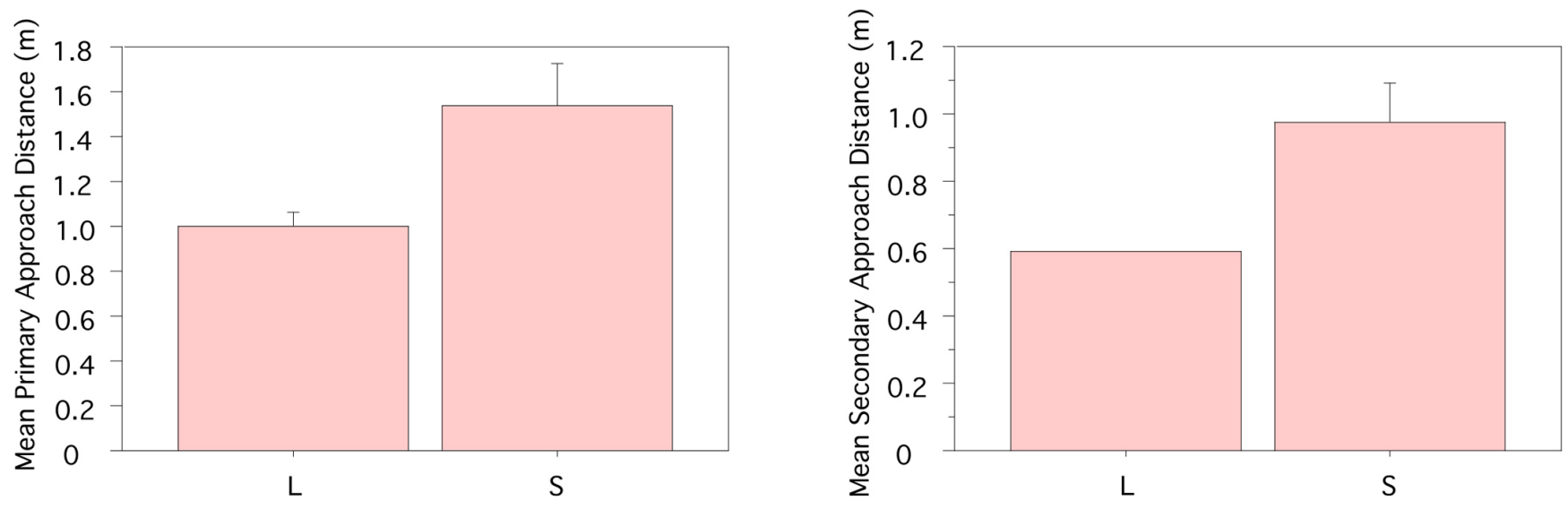

Fig. 7. Mean primary (left) and secondary (right) approach distances $(\mathrm{m}) . \mathrm{L}=$ adult males; $\mathrm{S}=$ subadult males and adult females.

facing up. Only ten individuals, eight of which were on the ground, were perched horizontally.

The mean primary approach distance (Fig. 7) of adult males $(0.99 \pm 0.07 \mathrm{~m}, 0.62-1.5 \mathrm{~m}, \mathrm{n}=17)$ was shorter than that of smaller individuals $(1.54 \pm 0.18 \mathrm{~m}, 0.51-2.6 \mathrm{~m}, \mathrm{n}=$ 17) but the difference was not significant (tied $Z=-1.751, P$ $=0.08$ ). The mean secondary approach distance (Fig. 7) of adult males $(0.59 \pm 0.00 \mathrm{~m}, 0.59 \mathrm{~m}, \mathrm{n}=2)$ also was shorter than that of smaller individuals $(0.97 \pm 0.12 \mathrm{~m}, 0.58-1.50$ $\mathrm{m}, \mathrm{n}=10$ ) but did not differ significantly (tied $\mathrm{Z}=-1.303$, $\mathrm{P}=0.19$ ). Those individuals for which secondary approach distances were recorded were among those with longer (generally upward) primary approach distances. Approach distances for all individuals were significantly greater (tied $\mathrm{Z}=$ $-2.503, \mathrm{P}=0.01)$ in the morning $(1.57 \pm 0.19 \mathrm{~m}, 0.56-2.60$ $\mathrm{m}, \mathrm{n}=12)$ than in the afternoon $(1.05 \pm 0.14 \mathrm{~m}, 0-2.50 \mathrm{~m}$, $\mathrm{n}=24$ ), even when the two individuals that allowed us to approach to within $1 \mathrm{~cm}$ (see below) were excluded (both were approached in the afternoon), the difference was significant (tied $\mathrm{Z}=-2.255, \mathrm{P}=0.02$ ).

Two individuals (both adult males) did not respond despite an approach to within $1 \mathrm{~cm}$. Eight of the other
17 adult males moved up (all had been facing up when approached) and six of them squirreled while climbing, seven squirreled immediately (four had been facing up, three down), and two jumped to another perch. Ten of 18 smaller individuals squirreled immediately (five had been facing up and five down), four moved up (all had been facing up) and two squirreled while climbing, two moved down (both had been facing down) and neither squirreled, and two jumped to another perch.

Focal animal observations of adult males lasted 2.5-10 $\min (5.7 \pm 0.6 \mathrm{~min})$, those for smaller individuals lasted 0.8 $10 \mathrm{~min}(6.2 \pm 0.9 \mathrm{~min})$. Rates (per min) of behaviors (Table 1) did not differ significantly between males and females (moves/minute: tied $\mathrm{Z}=-0.230, \mathrm{P}=0.81$; head turns $/ \mathrm{min}$ : $\operatorname{tied~} \mathrm{Z}=-1.356, \mathrm{P}=0.18$; head bobs $/ \mathrm{min}$ : tied $\mathrm{Z}=0.000, \mathrm{P}>$ $0.99)$, but only males extended dewlaps and engaged in pushups. Dewlap extensions and pushups were frequently paired in what were either territorial or mating displays (Jenssen 1983; Fig. 8). In aggregate, the 14 males spent about $3 \%$ of their time displaying, but one male invested $17 \%$ of his time displaying and another individual spent $16 \%$ of his time with dewlap extended and $31 \%$ doing pushups.

Table 1. Rates of behaviors (per min) of 14 adult male Anolis distichus ocior and 14 adult females during focal animal observations. Each entry consists of a mean \pm one standard error followed by the range in parentheses.

\begin{tabular}{lccccc} 
Sex & Moves & Head turns & Head bobs & Dewlap extensions & Pushups \\
\hline Males & $2.11 \pm 0.33$ & $0.72 \pm 0.25$ & $0.15 \pm 0.09$ & $0.20 \pm 0.08$ & $(0-0.79)$ \\
\hline & $(0.33-4.43)$ & $(0-2.34)$ & $(0-1.20)$ & & $0.20 \pm 0.12$ \\
\hline Females & $2.28 \pm 0.52$ & $1.40-0.36$ & $0.09 \pm 0.04$ & $-1.58)$ & - \\
\hline & $(0.44-7.90)$ & $(0-3.59)$ & $(0-0.49)$ & - & - \\
\hline
\end{tabular}




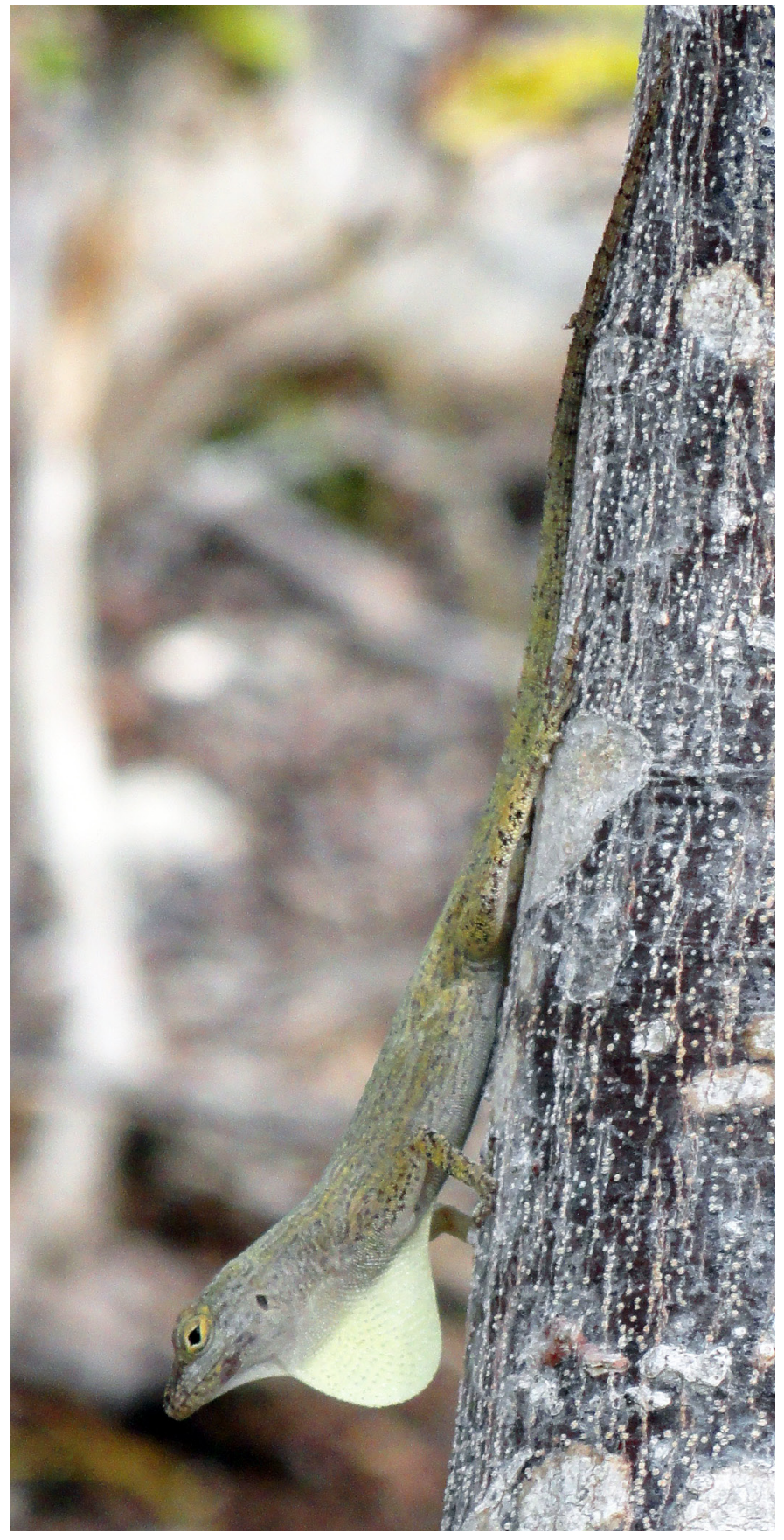

Fig. 8. An adult male San Salvador Bark Anole (Anolis distichus ocior) displaying. Photograph by Guillermo G. Zuniga.

\section{Discussion}

Anolis distichus is a polytypic species with a broad distribution encompassing a tremendous variety of habitats. Although most of our observations on San Salvador correspond to results of studies conducted on populations elsewhere in the species' range, deviations from predictions probably are attributable to unique local conditions. These reflect the ecological versatility of a species that has in many instances shown considerable tolerance for not only varied natural but often dramatically altered habitats (e.g., Powell and Henderson 2008).
Our density estimate is highly conservative because it was based solely on individuals observed during a single survey, which might account for why, at least in part, it is lower than most previous estimates, but the very small size of the patch of suitable habitat also undoubtedly contributed to the relatively low density. Schoener and Schoener (1978) listed densities of 1,070-5,460/ha in various Bahamian habitats; Schoener (1979) provided densities on Bimini in "short-blackland" habitat $(1,180 /$ ha), in "forest-path" habitat $(750 /$ ha), and in Terminalia habitat $(3,830 / \mathrm{ha})$; Schoener and Schoener (1980a, 1980b) estimated values for various habitats on two Bahamian islands of 0-5,480/ha; Cast et al. (2000), depending on the method used, listed densities of 1,694 or 1,701/ha in rainforest interior and 1,764 or $3,853 /$ ha along forest edge on Hispaniola; and Sifers et al. (2001), also on Hispaniola, estimated densities of $257-444 /$ ha concentrated along edges at two cloud-forest sites. Most of the other estimates were in habitats supporting four or more species of anoles, whereas only two species have been recorded from San Salvador (Hillbrand et al. 2011; Buckner et al. 2012). We saw only a single male Cuban Brown Anole (Anolis sagrei) in our study area.

As predicted, Bark Anoles at our site were active throughout the day. This corresponded to what has been reported for most West Indian anoles, as was a peak in activity during the morning with a decline corresponding to the hottest times of day (Henderson and Powell 2009 and references therein). However, we did not see a predicted secondary peak late in the day as Hillbrand et al. (2011) had described for Bark Anoles on San Salvador and which is characteristic of many West Indian lizards, including many anoles (e.g., Henderson and Powell 2009). Weather conditions were normal for May, so the lack of a bimodal activity pattern might be a site-specific or seasonal phenomenon.

As predicted, mean perch height of adult males was higher than that of subadult males and females. Since both sexes largely consume ants (Schoener 1968, 1979; Schoener and Schoener 1980a; Cullen and Powell 1994) and ants appeared equally abundant on trunks of trees at the heights at which anoles were perched, the differential in perch heights suggests that males sought higher perches from which they could better monitor their territories and the females therein (Scott et al. 1976). Similar to results presented by Schoener (1968), perch diameters did not differ significantly, presumably reflecting the almost exclusive use of trunks with diameters that varied little at the heights at which most observations were made. Schoener (1968) also noted that Bark Anoles were never found on leaves, which was consistent with our observations.

The paucity of anoles on the ground mirrored observations of Schoener (1968), Lister (1976), and Moermond (1979). Moster et al. (1992), in a study of Anolis brevirostris, another trunk ecomorph, noted that anoles foraged on the 
ground more frequently when larger ground-dwelling lizards and putative predators (e.g., Ameiva spp., Leiocephalus spp.) were rare or absent. No terrestrial lizards were present at the site on San Salvador (and we encountered only the one Anolis sagrei in the study area). The lack of cover on the ground (Fig. 3) might account for the apparent reluctance of these anoles to exploit terrestrial prey - or the apparent abundance of prey on trunks (ants were frequently observed on all trees at the site) could preclude the need to diverge from preferred microhabitats.

The vast majority of individuals were in full shade regardless of time of day. This was suggestive of thermal conformity and corresponded to what has been described for many anoles (e.g., Ruibal 1961; Losos 2009 and references therein), especially in heavily shaded lowland situations where temperatures are generally in the range at which lizards can function effectively and the costs of thermoregulation are greater than the prospective benefits (Losos 2009 and references therein). Although anoles in open or edge habitats tend to bask frequently (e.g., Huey and Slatkin 1976) and our site provided ample edges where basking sites were accessible and within short distances, the minimal energy expenditure and increased exposure to predators (primarily avian) appeared to negate any potential benefits.

Most anoles were facing downward (the "watch position" of Hillbrand et al. 2011), presumably to better monitor potential predators, competitors, and possible mates (e.g., Scott et al. 1976), but many (34) were facing up. Upward orientation often is associated with escape behavior (e.g., Henderson and Powell 2009) or movement to higher, more intensely insolated perches early in the day (R. Powell, pers. comm.), but observations were limited to undisturbed animals and the relative frequency of upward-facing anoles was not higher during cooler, early-morning hours. Consequently, we cannot explain the relatively large number of upward-facing lizards. The paucity of individuals (2) perching horizontally almost certainly reflected the vertical structure of the trees in the study plot and the ecomophology of the species (i.e., the most frequently used trunk habitats were almost inevitably vertical).

Adult males tolerated closer approaches than smaller individuals, in line with our prediction. However, our approach distances were longer than those reported by Schneider et al. (2000) for Bark Anoles on Hispaniola, although several individuals allowed very close approaches, apparently relying on crypsis or agility (Oliver 1948) to escape. That lizards responded at greater distances in the morning than in the afternoon probably indicated a greater degree of caution that might be a consequence of slightly lower body temperatures that could slow reactions.

As Schneider et al. (2000) and Hillbrand et al. (2011) noted previously, squirreling was the most frequently used mode of escape. Moving up was more prevalent than moving down, presumably because the canopy provided cover miss- ing near ground level at this site. Jumping was rare and largely limited to a few trees with multiple trunks. On Hispaniola, Schneider et al. (2000) observed more frequent jumps, but most trunks at this study site were widely spaced, providing few targets for prospective jumpers.

Contrary to our prediction, adult males did not move more frequently than smaller individuals, nor were differences in head-turn and bobbing rates significant. However, lizards in both size classes moved more frequently than indicated by Johnson et al. (2008), but the percentage of time males spent displaying was less than that recorded by J.B. Losos (in Henderson and Powell 2009). Although May is the very beginning of the rainy season, the time when many tropical lizards mate (e.g., Henderson and Powell 2009 and references therein), we observed no copulations. Reproductive activity in xeric habitats on San Salvador might be delayed until the actual onset of seasonal rains, as was observed in a population of Leiocephalus barahonensis on the Barahona Peninsula of Hispaniola (Micco et al. 1998 ["1997"]). Alternatively, the relatively little time spent displaying could reflect the relative isolation of individual trunks, which presumably reduced the frequency of encounters between males, rendering the need for frequent territorial displays unnecessary.

\section{Acknowledgements}

This project was in partial fulfillment of requirements for an Avila University class (IS 337 Tropical Culture and Nature: A History of Invasions; David Wissmann, Tyrun Flaherty, and Robert Powell, professors). We thank the staff of the Gerace Research Centre for providing us with the opportunity to conduct this investigation, making us feel welcome, and tolerating our antics.

\section{Literature Cited}

Buckner, S.D., R. Franz, and R.G. Reynolds. 2012. Bahama Islands and Turks \& Caicos Islands, pp. 93-110. In: R. Powell and R.W. Henderson (eds.), Island lists of West Indian amphibians and reptiles. Bulletin of the Florida Museum of Natural History 51: 85-166.

Cast, E.E., M.E. Gifford, K.R. Schneider, A.J. Hardwick, J.S. Parmerlee, Jr., and R. Powell. 2000. Natural history of an anoline lizard community in the Sierra de Baoruco, República Dominicana. Caribbean Journal of Science 36: 258-266.

Cullen, D.J. and R. Powell. 1994. A comparison of food habits of a montane and a lowland population of Anolis distichus (Lacertilia: Polychrotidae) from the Dominican Republic. Bulletin of the Maryland Herpetological Society 30: 62-66.

Fitch, H.S., R.W. Henderson, and H. Guarisco. 1989. Aspects of the ecology of an introduced anole: Anolis cristatellus in the Dominican Republic. AmphibiaReptilia 10: 307-320.

Henderson, R.W. and R. Powell. 2009. Natural History of West Indian Reptiles and Amphibians. University of Florida Press, Gainesville, Florida.

Hillbrand, P.A., A.T. Sloan, and W.K. Hayes. 2011. The terrestrial reptiles of San Salvador Island, Bahamas. Reptiles \& Amphibians 18: 154-166.

Huey, R.B. and M. Slatkin. 1976. Cost and benefits of lizard thermoregulation. Quarterly Review of Biology 51: 363-384.

Jenssen, T.A. 1983. Display behavior of two Haitian lizards, Anolis cybotes and Anolis distichus, pp. 552-569. In: A.G.J. Rhodin and K. Miyata (eds.), Advance in Herpetology and Evolutionary Biology: Essays in Honor of Ernest E. Williams. Museum of Comparative Zoology, Harvard University, Cambridge, Massachusetts. 
Johnson, M.A., M. Leal, L. Rodríguez Schettino, A. Chamizo Lara, L.J. Revell, and J.B. Losos. 2008. A phylogenetic perspective on foraging mode evolution and habitat use in West Indian Anolis lizards. Animal Behaviour 75: 555-563.

Lister, B.C. 1976. The nature of niche expansion in West Indian Anolis lizards. I. Ecological consequences of reduced competition. Evolution 30: 659-676.

Losos, J.B. 2009. Lizards in an Evolutionary Tree: Ecology and Adaptive Radiation of Anolis. University of California Press, Berkeley and Los Angeles.

Mertens, R. 1939. Herpetologische Ergebnisse einer Reise nach der Insel Hispaniola, Westindien. Abhandlungen der Senckenbergischen Naturforschenden Gesellschaft 449: $1-84$.

Micco, S.M., G.J. Lahey, R.A. Sosa, R. Powell, E.J. Censky, and J.S. Parmerlee, Jr. 1998 ("1997"). Natural history of Leiocephalus barahonensis (Tropiduridae) on the Península de Barahona, Hispaniola: An examination of two populations. Herpetological Natural History 5: 147-156.

Moermond, T.C. 1979. Habitat constraints on the behavior, morphology, and community structure of Anolis lizards. Ecology 60: 152-164.

Moster, J.A., R. Powell, J.S. Parmerlee, Jr., D.D. Smith, and A. Lathrop. 1992. Natural history notes on a small population of Anolis brevirostris (Sauria: Polychridae) from altered habitat in the Dominican Republic. Bulletin of the Maryland Herpetological Society 28: 150-161.

Oliver, J.A. 1948. The anoline lizards of Bimini, Bahamas. American Museum Novitates 1383: 1-36.

Paterson, A.V. 1999. Effects of prey availability on perch heights of female Bark Anoles, Anolis distichus. Herpetologica 55: 242-247.

Powell, R. and R.W. Henderson. 2008. Urban herpetology in the West Indies, pp. 389-404. In: J.C. Mitchell, R.E. Jung Brown, and B. Bartholomew (eds.), Urban Herpetology. Herpetological Conservation, volume 3. Society for the Study of Amphibians and Reptiles, Salt Lake City, Utah.

Rand, A.S. 1962. Notes on Hispaniolan herpetology. 5. The natural history of three sympatric species of Anolis. Breviora 154: 1-15.
Rand, A.S. and E.E. Williams. 1969. The anoles of La Palma: Aspects of their ecological relationships. Breviora 327: 1-18.

Ruibal, R. 1961. Thermal relations of five species of tropical lizards. Evolution 15: 98-111.

Schneider, K.R., R. Powell, and J.S. Parmerlee, Jr. 2000 Escape behavior of Anolis lizards from the Sierra de Baoruco, Dominican Republic. Caribbean Journal of Science 36: 321-323.

Schoener, T.W. 1968. The Anolis lizards of Bimini: Resource partitioning in a complex fauna. Ecology 49: 704-726.

Schoener, T.W. 1979. Feeding, spacing, and growth in the four species of Bimini Anolis lizards. National Geographic Society Research Reports, 1970 Projects: 479-485.

Schoener, T.W. 1988. Testing for non-randomness in sizes and habitats of West Indian lizards: Choice of species pool affects conclusions from null models. Evolutionary Ecology 2: 1-26.

Schoener, T.W. and A. Schoener. 1978. Estimating and interpreting body-size growth in some Anolis lizards. Copeia 1978: 390-405.

Schoener, T.W. and A. Schoener. 1980a. Densities, sex ratios, and population structure in four species of Bahamian Anolis lizards. Journal of Animal Ecology 49: 19-53.

Schoener, T.W. and A. Schoener. 1980b. Ecological and demographic correlates of injury rates in some Bahamian Anolis lizards. Copeia 1980: 839-850.

Schwartz, A. and R.W. Henderson. 1991. Amphibians and Reptiles of the West Indies: Descriptions, Distributions, and Natural History. University of Florida Press, Gainesville.

Scott, N.J., Jr., D.E. Wilson, C. Jones, and R.M. Andrews. 1976. The choice of perch dimensions by lizards of the genus Anolis (Reptilia, Lacertilia, Iguanidae). Journal of Herpetology 10: 75-84.

Sifers, S.M., M.L. Yeska, Y.M. Ramos, R. Powell, and J.S. Parmerlee, Jr. 2001. Anolis lizards restricted to altered edge habitats in a Hispaniolan cloud forest. Caribbean Journal of Science 37: 55-62. 